\title{
Humanistic Medicine, a Forgotten Concept? The Correct Approach in Palliative Care of Chronic Patients
}

\author{
Sorin Albu', Septimiu Voidăzan² \\ 1 Department of Physiology, University of Medicine and Pharmacy, Tîrgu Mureș, Romania \\ 2 Department of Epidemiology, University of Medicine and Pharmacy, Tîrgu Mureș, Romania
}

\section{CORRESPONDENCE}

\section{Septimiu Voidăzan}

Str. Gheorghe Marinescu nr. 38

540142 Tîrgu Mureș, Romania

Tel: +40 265215551

E-mail: voidazan.septimiu@umftgm.ro

\section{ARTICLE HISTORY}

Received: 2 November, 2016

Accepted: 20 November, 2016

\section{ABSTRACT}

Palliative care in Romania is a relatively new emerging field. Challenges of this specialty, its uniqueness and the several problems posed by a particular category of patients, the chronically ill patients, make this medical specialty a particularly complex one in certain situations, requiring a multidisciplinary team well-prepared in terms of theory and practice. Unlike in the case of most medical specialties, particular emphasis is laid on the "human" side of medical care, this specialty introducing the concept of "total pain".

Keywords: chronic patient, holistic care, palliative care

\section{INTRODUCTION}

According to the World Health Organization, palliative care (PC) is defined as follows: "Palliative care is an approach that improves the quality of life of patients and their families facing the problem associated with life-threatening illness, through the prevention and relief of suffering by means of early identification and impeccable assessment and treatment of pain and other problems, physical, psychosocial and spiritual."1

In patients with chronic diseases, the focus is on the comfort of the patient. This comfort also implies other specific aspects of a chronic patient and particularly an oncological patient: namely the physical, mental, social, and spiritual aspect. In PC as well, treating the symptoms of a chronic patient has great importance, but is not the only aspect to consider.

The Eastern Cooperative Oncology Group (ECOG) Performance Status describes the patients' level of functioning in terms of their ability to care for themselves, daily activity, and physical ability, with the following classification: grade 0 - fully active patient, able to perform the same tasks as before the disease without restrictions; grade 1 - restrictions in carrying out strenuous activities but mobile patient, able to carry out light/sedentary/office work; grade 2 - mobile 
TABLE 1. Measures for healthcare professionals to take in palliative medicine

\begin{tabular}{l} 
What to do? \\
\hline To admit to our discomfort related to the limitations of treatments we offer \\
To inform about the different options for care, the probability of success of a treatment, and its \\
possible side effects \\
To define more clearly the sources of information for patients and their families, about their prog- \\
nosis, about alternatives, expected results, and ways to make the necessary decisions \\
Not to consider the death of a person as a failure of medicine - and to return to the decency to \\
consider death as a natural and essential stage of life \\
Not to consider the death of a patient as a personal or professional failure \\
We are responsible, as professionals, to educate patients, families and the whole society that \\
death is not something to be avoided at all costs. \\
To promote palliative education, so that suffering be avoided and alleviated. \\
\hline
\end{tabular}

and capable of self-care but unable of any kind of work, active for over $50 \%$ of time; grade 3 - capable of limited selfcare but unable of any kind of work, active for over $50 \%$ of time; grade 4 - completely bedridden, unable of self-care. ${ }^{2}$

The visual analog scale is a one-dimensional scale that measures the intensity of pain. The patient places a cursor on a line, which has marked absence of pain at the left end, and the worst pain imaginable at the right end, depending on how intense it is felt. The back of this scale is scored from 0 to 10 , thus allowing quantification of the intensity of pain experienced by the patient. ${ }^{3,4}$

\section{CASE PRESENTATION}

Bioethical aspects of PC can be better understood by presenting the case of a 53-year-old patient, admitted to a palliative care ward for prostate carcinoma, multiple bone metastases, retroperitoneal lymph node metastasis, and liver metastasis.

The patient was diagnosed with prostate carcinoma and had received hormonal treatment a year before his admission to PC. About half a year after the diagnosis, multiple metastases were detected. On admission, the patient had a high intensity pain syndrome and edema of the left lower limb. The patient had an ECOG score of 3 on admission and 3 upon hospital discharge. The visual analog pain score was 9 on admission and 3 upon hospital discharge. During hospitalization, the patient has been treated with major analgesics, non-steroidal anti-inflammatory medication, carbamazepine, sulodexide, iron, dexamethasone and nylex.

The particularities of this case were that the patient had been informed about his diagnosis, had accepted it and had been compliant to the treatment. Furthermore, the patient had future plans to solve his business problems, to not get his family worried and also to go fishing. The patient had a good sense of humor, was of orthodox religion and had received spiritual care at home. We did not encounter any difficulties in communicating with the patient, but he had a family problem, namely that his son was abroad.

During the patient's last 3-4 days at home, he could not self-administer morphine, and his spouse was afraid of morphine, thus only oral MST was administered, with poor analgesic control of symptoms. The patient was admitted to the hospital in the ante finem period and deceased hours after hospitalization.

\section{DISCUSSIONS}

The proper measures that should be taken by medical professionals in such cases of palliative care are listed in Table 1.

Mental problems, and especially depression in oncology patients, are one of the most common emotional disorders. ${ }^{5}$

There are two particular problems linked to depression in PC: 1) psychiatric signs and symptoms diagnosed as depression, and 2) disorders specific to depression defined by diagnostic criteria. ${ }^{6}$ Although the trend is that most doctors define depression according to the first criterion, psychiatrists define depression according to the second criterion. ${ }^{7}$ These two different approaches have implications for the treatment of depression. For example, antidepressant treatment is effective in patients suffering from depression, but it has no effect on patients whose symptoms suggest that the depression lies in their adaptation to the illness. ${ }^{8}$ The Expert Working Group (EWG) of the European Association for Palliative Care (EAPC) recommends to use the diagnostic criteria according to the Diagnostic and Statistical Manual of Mental Disorders (DSM-IV) of the American Psychiatric Association. Unfortunately, depression in PC is often underdiagnosed and undertreated. ${ }^{9}$

There is another, psychosocial aspect of PC, defined by the National Council for Hospice and Specialist Pal- 
liative Care Services as psychological and social care for the welfare of patients and their families and/or carers and includes aspects of self-esteem by adapting to the disease and its consequences, aspects of communication and networking, as well as social aspects. ${ }^{10}$

Some patients face a stigmatism from the society, that is, a negative assessment of the society towards the behavior or characteristics of an individual. ${ }^{11}$

Another important aspect of PC is the spiritual one. This was defined by the National Consensus Project for Quality of Palliative Care as "the aspect of humanity that refers to the way individuals seek and express meaning and purpose and the way they experience their connectedness to the moment, to self, to others, to nature and to the significant or sacred". ${ }^{12}$ Although patients want to discuss about their beliefs and spiritual needs, these needs are neglected or underappreciated by the medical staff. ${ }^{13}$ Studies conducted in countries with a tradition of PC emphasize this. An American study by Balboni et al. showed that of 230 patients with advanced cancer diseases, $72 \%$ reported that their spiritual needs did not receive or received very little spiritual counseling from the health system. ${ }^{14}$ What would be the reasons for this neglect of spiritual counseling on behalf of the PC staff? One reason is mistrust in the spiritual counseling of health professionals working in palliative care. ${ }^{15}$ Another reason is the lack of evidence or better evidence proving health professionals that this kind of counseling in medical practice has advantages. ${ }^{16}$

The concept of "total pain" is not easily addressed when PC patients are involved. Almost invariably, PC communication is a central element of therapy. This does not only imply verbal communication, but also the so-called body language, using physical contact to increase the patients' confidence, the ability to listen and understand what the patient or his family say, the use of open questions, exploring the emotions of the patient through a compassionate reply, establishing a strategy together with the patient. ${ }^{17}$ Observing the proximity between the doctor and the patient in various situations emphasizes the fact that patients frequently offer nonverbal cues instead of verbally expressing their emotions and concerns. In most cases, these indications displayed by the patient during consultation are overlooked by the doctor. ${ }^{18}$

\section{CONCLUSION}

Palliative care is a complex specialty that requires a welltrained interdisciplinary team to face the specific challeng- es posed by a special category of patients, namely chronic patients. The concept of "total pain" includes the physical, mental, social, and spiritual side of the chronic patient, while the family of the patient is an important support element that also needs support from the PC team.

\section{CONFLICT OF INTEREST}

Nothing to declare.

\section{REFERENCES}

1. Gehlert S, Browne TA. The Handbook of Health Social Work, Hoboken, New Jersey: John Wiley \& Sons; 2006; p. 58-62

2. Oken M, Creech R, Tormey D, et al. Toxicity and response criteria of the Eastern Cooperative Oncology Group. Am J Clin Oncol. 1982;5:649-655.

3. Selman L, Young T, Vermandere M, Stirling I, Leget C, on behalf of the Research Subgroup of the European Association for Palliative Care Spiritual Care Taskforce. An International Survey of Palliative Care Researchers and Clinicians. J Pain Symptom Manage. 2014;4:518-531.

4. Antunes B, Fliss M, Bausewein C, et al. Screening for Depression in Advanced Disease: Psychometric Properties, Sensitivity, and Specificity of Two Items of the Palliative Care Outcome Scale (POS). J Pain Symptom Manage. 2015;49:277-288.

5. Castelli L, Binaschi L, Caldera P, Mussa A, Torta R. Fast screening of depression in cancer patients: the effectiveness of the HADS. Eur $J$ Cancer Care. 2011;20:528-533

6. Stiefel F, Die Trill M, Berney A, Olarte JM, Razavi A. Depression in palliative care: a pragmatic report from the Expert Working Group of the European Association for Palliative Care. Support Care Cancer. 2001;9:477-488.

7. Regier DA, Kessler LG, Burns BJ, Goldberg ID. The need for a psychosocial classification system in primary-care settings. Int J Ment Health. 1979;8:1629.

8. Berney A, Stiefel F, Mazzocato C, Buclin T. Psychopharmacology in supportive care in cancer: a review for the clinician. III. Antidepressants. Support Care Cancer. 2000;8:278-286.

9. Neron S, Correa JA, Dajczman E, Kasymjanova G, Kreisman H, Small D. Screening for depressive symptoms in patients with unrespectable lung cancer. Support Care Cancer. 2007:15:1207-1212.

10. What do we mean by 'psychosocial'? A discussion paper on use of the concept within palliative care. The National Council for Palliative Care Mar. 2000. Available online at: http://www.ncpc.org.uk/publications/archives. html

11. van Gennip IE, Pasman HR, Oosterveld-Vlug MG, Willems DL, OnwuteakaPhilipsen BD. The development of a model of dignity in illness based on qualitative interviews with seriously ill patients. Int J Nurs Stud. 2013;50:1080-1089.

12. National Consensus Project. Clinical practice guidelines 2013. Available online at: http:/www.nationalconsensusproject.org/NCP. [Accessed Janury 2016]

13. Astrow AB, Wexler A, Texeira K, He MK, Sulmasy DP. Is failure to meet spiritual needs associated with cancer patients' perceptions of quality of care and their satisfaction with care? J Clin Oncol. 2007;25:5753-5757.

14. Balboni TA, Vanderwerker LC, Block SD, et al. Religiousness and spiritual support among advanced cancer patients and associations with end-of-life treatment preferences and quality of life. J Clin Oncol. 2007;25:555-560.

15. Belcham C. Spirituality in occupational therapy: theory in practice? The British Journal of Occupational Therapy. 2004;67:39-46.

16. Candy B, Jones L, Varagunam M, Speck P, Tookman A, King M. Spiritual and religious interventions for well-being of adults in the terminal phase of disease. Cochrane Database Syst Rev. 2012;(5):CD007544.

17. Buckman R. Communication skills in palliative care. a practical guide. Neuro/ Clin. 2001;19:277-294

18. Levinson W, Gorawara-Bhat R, Lamb J. A study of patient clues and physician responses in primary care and surgical settings. JAMA. 2000;284:1021-1027. 